http://jmscr.igmpublication.org/home/

ISSN (e)-2347-176x ISSN (p) 2455-0450

crossref DOI: https://dx.doi.org/10.18535/jmscr/v7i7.105

Journal Of Medical Science And Clinical Research

IGM Publication

An Official Publication of IGM Publication

\title{
To study the association of chronic spontaneous urticaria with anti thyroid peroxidase antibody and ASST
}

\author{
Authors \\ Dr Rashmi Singh*, Dr (Prof) Rana Gopal Singh \\ Department of Dermatology, Heritage Institute of Medical Sciences, Bhadwar bypass, Varanasi, \\ Uttar Pradesh \\ *Corresponding Author \\ Dr Rashmi Singh \\ C-33/58 B2K, Behind sunbeam school, Sigra, Varanasi, UP, India
}

\begin{abstract}
Background: Urticaria is a disease with weals and itching seen in all age groups. It can be acute or chronic, and chronic can be further subdivided into chronic inducible urticaria and chronic spontaneous urticaria.

Till date some many antibodies have been found to be associated with chronic spontaneous urticaria. Autologous serum sensitivity test has emerged as one of the invasive investigations being tried in detecting the autoimmune nature of the disease.

Through this study, we are trying to find out the association of antithyroid peroxidase antibody (anti TPO) with CSU (chronic spontaneous urticaria) and correlate the severity of CSU with ASST positivity.

Objectives: To find out if there is any association of chronic autoimmune urticaria with anti TPO and ASST to correlate its severity with them.

Method: Ours was a crossectional study whereby we have investigated all the enrolled patients for anti TPO and performed ASST on them. A total of 137 consecutive patients were enrolled and investigated for serum anti TPO and ASST performed on them. The datas were analysed using SPSS software 2019 version.

Result: In this study anti TPO antibodies and ASST was found to be positive in patients of CSU. While anti TPO has come out to be a screening tool and ASST a better diagnostic tool.

Conclusion: We can conclude from the study that CSU is associated with anti TPO.

Keywords: CSU, Anti TPO, ASST, association.
\end{abstract}

\section{Introduction}

Chronic urticaria (CU) is defined by the presence of recurrent urticaria (hives), with or without angioedema, for a period of six weeks or longer ${ }^{(1,2)}$. As many as 40-50 percent of patients with CU have accompanying episodes of angioedema $^{(2)}$. No external allergic cause or contributing disease process can be identified in
80 to 90 percent of adults and children with $\mathrm{CU}$. There are several theories regarding the pathogenesis of chronic idiopathic urticaria (CIU) or chronic spontaneous urticaria (CSU), none of which have been conclusively established. $\mathrm{CU}$ is a self-limited disorder in most patients, although the average duration of disease is two to five years. ${ }^{(3-}$ 5) The first indications that $\mathrm{CU}$ might have an 
autoimmune origin were noted by Leznoff et al who suggested that there is an increased incidence of antithyroid antibodies (antimicrosomal and antithyroglobulin) in approximately $12 \%$ to $15 \%$ of such patients. ${ }^{(3,4)}$ The autoimmune subgroup of chronic urticaria has shown association with antithyroid antibodies. ${ }^{(6)}$ The pathogenesis suggested till dateis the presence of $\mathrm{IgG}$ antibody to the alpha subunit of the $\operatorname{IgE}$ receptorin $35-40 \%$ cases of CSU. ${ }^{(7)}$ Further these antibodies have been found to be usually reactive with unoccupied $\operatorname{IgE}$ receptors or $\operatorname{IgG} \mathrm{Ab}$ to $\operatorname{IgE}$ in $5-10 \%$ \& the IgG subclass most commonly found to be pathogenic in cases of CSU are $\operatorname{IgG}(1) \& \operatorname{IgG}^{(3)(8)}$. Presently, ASST is one of the most useful tests for confirming a diagnosis of chronic autoimmune urticaria with sensitivity \& specificity respectively of $65-81 \%$ \& $71-78 \%{ }^{(9)}$. Basophils being an important factor in the pathogenesis of CSU, the basophil activation test can be a useful screening tool for confirmation of autoimmune basis of the disease but further confirmatory studies are needed for its acceptance. ${ }^{(10)}$ Here comes the role of ASST which though invasive can be a useful tool for confirming a case of CSU as CAU. Not only this, ASST positive patients are seen to have a severe course of disease thereby requiring high dose of antihistamines for longer duration.

\section{Material and Methods}

After getting ethical clearance from the ethical committee in the Heritage Institute of Medical College in November 2017, based on previous prevalence studies 138 consecutive patients of chronic urticaria were included in the study. After written consent, a detailed history and clinical examination were recorded for each patient.

\section{Inclusion Criteria: Patients of chronic} spontaneous urticaria were identified based on history, examination and routine laboratory investigations. History included use of drug for control of urticaria or drugs for other ailments known to suppress urticaria.

Routine investigations included complete blood count, stool examination, urine microscopy and thyroid profile etc., to rule out possible causes of urticaria.

Exclusion Criteria: 1.Patients having acute urticaria ( $<6$ weeks), physical urticarias including symptomatic dermographism (mechanical urticaria), solar urticaria, cold urticaria, pressure urticaria, cholinergic urticaria, contact urticaria syndromes, urticaria pigmentosa (mastocytosis), urticarial vasculitis. 2. Patients on immunosuppressive drugs during the last four weeks.

All patients with chronic spontaneous urticaria (CSU) were made to undergo antiTPO using chemiluminescence assay method.

ASST was performed on all patients diagnosed clinically as a case of CSU. For ASST $2 \mathrm{ml}$ blood was drawn by venepuncture and made to stand for 15 minutes to clot at room temperature then serum was separated by centrifugation at $500 \mathrm{rpm}$ and was used immediately for ASST. Approximately $0.05 \mathrm{ml}$ ( 2 units) in insulin syringe was drawn and injected intradermally on flexural aspect of the left forearm. Normal saline and histamine diphosphate was used as positive and negative control keeping a gap of $5 \mathrm{~cm}$ between the three test site. The test was considered positive when wheal size at ASST site was $1.5 \mathrm{~mm} \geq$ than wheal at saline control site.

\section{Data Analysis}

All data was recorded and processed using SPSS version 12.0. While quantitative variables were expressed as mean $( \pm \mathrm{SD})$, qualitative variables were expressed as frequencies and were compared using chi-square test .A p-value of $<0.05$ was considered significant. Mc Nemar test was performed and kappa calculated to see the agreement or disagreement between ASST and anti TPO.

\section{Results and Discussion}

Influence of demography on UAS score

As shown in Table 1 positive anti TPO was seen in more number of male patients than female patients but results were insignificant $(p>0.05)$. Not only this, even age did not show any 
significant association with anti TPO in CSU patients. But anti TPO has shown a strong association with UAS7 score, hence with severity $(\mathrm{p}<0.05)$.

Now, as in Table 3, UAS score is not associated with sex of the affected individual, we can conclude that female sex is not associated with severe form of CSU.

Has demography any effect on ASST \& anti TPO $?$

\begin{tabular}{|l|l|l|l|}
\hline Parameters & $\begin{array}{l}\text { Vikram kumar } \\
\text { AG et al } \\
\text { 2014.(11) }\end{array}$ & $\begin{array}{l}\text { Najafipour M } \\
\text { et al } \\
\text { 2018.(12) }\end{array}$ & $\begin{array}{l}\text { Present } \\
\text { study }\end{array}$ \\
\hline Age on ASST & Present & & Absent \\
\hline Sex on ASST & Present & & Absent \\
\hline Age on anti TPO & & Absent & Absent \\
\hline Sex on anti TPO & & Absent & Absent \\
\hline
\end{tabular}

Has disease severity anything to do with ASST \& anti TPO?

Since, chi-square and p-value $(<0.00001)$ shows significant association of ASST as well as anti TPO with UAS score (table 4\&5), this suggests that, in our study both ASST \&anti TPO have strong association with severity of CSU

What other studies have to say?

Comparison with our study

\begin{tabular}{|c|c|c|c|c|}
\hline Study Parameter & $\begin{array}{l}\text { Sabroe } \\
\text { et } \mathrm{al}^{10}\end{array}$ & $\begin{array}{l}\text { Kulthanan } \\
\text { et al }^{(13)}\end{array}$ & Georgeetal $^{(14)}$ & $\begin{array}{c}\text { Present } \\
\text { study }\end{array}$ \\
\hline ASST & Present & Absent & Present & Present \\
\hline $\begin{array}{l}\text { Autoantibodies } \\
\text { (Serum IgE, } \\
\text { Anti TPO, } \\
\text { anti FCerlantibody }\end{array}$ & Absent & Absent & Absent & Present \\
\hline
\end{tabular}

Anti TPO and ASST in CSU: associated or not ? See table 5

Now, since both anti TPO and ASST are positive in greater number of patients of CSU, autoimmune basis of CSU is quite evident. Both Mcnemar test \& kappa value denote that ASST is a better tool than anti TPO in excluding the cases of chronic autoimmune urticaria while the latter is a better option for screening cases of CAU.

Let's have a look at previous studies and compare them with ours.

In a study done by Letznoff et al in1989 \&Yoko kikuchi and his colleagues in 2003, significant association was reported between anti TPO antibodies and ASST positivity in case of chronic urticaria $^{(4,15)}$. The findings of our study were inconsistent with these results, as in our study kappa value (-0.407) showed disagreement between antiTPO and ASST results. Even more, our results were unidentical to that of studies done by Bakos et al \& O' Donell et al who have reported significant association between anti TPO $\mathrm{Ab}$ and ASST positivity. ${ }^{(16,17))}$

Though our findings were incomparable to the reports of Yadav et al and Jindal et al in 2017, who found no significant association between AMA \& CAU.(18,19), but were comparable to the study done by Aamir IS, Tauheed S, Majid S, Atif A who found that out of 47 patients diagnosed with chronic urticaria $42.65 \%$ had elevated anti thyroglobulin $\mathrm{ab}$ and $57.4 \%$ had raised ant microsomal ab levels. ${ }^{(20)}$

\section{Highlights}

\# UAS 7 score higher in individuals with positive anti TPO.

UAS7 score higher in individuals with positive ASST.

No sex predilection in CSU patients.

All three of UAS score, anti TPO, ASST should be done in CSU patients.

Anti TPO having higher sensitivity than ASST is a better screening tool for CSU patients.

Table 1: Age Distribution of the Participants

\begin{tabular}{|l|c|c|c|c|}
\hline & Mean & SD & Minimum & Maximum \\
\hline Age (Years) & 33.38 & 9.99 & 10 & 65 \\
\hline
\end{tabular}

The mean age of the participants was $33.38( \pm 9.99)$ years. The age ranged from $10-65$ years. 


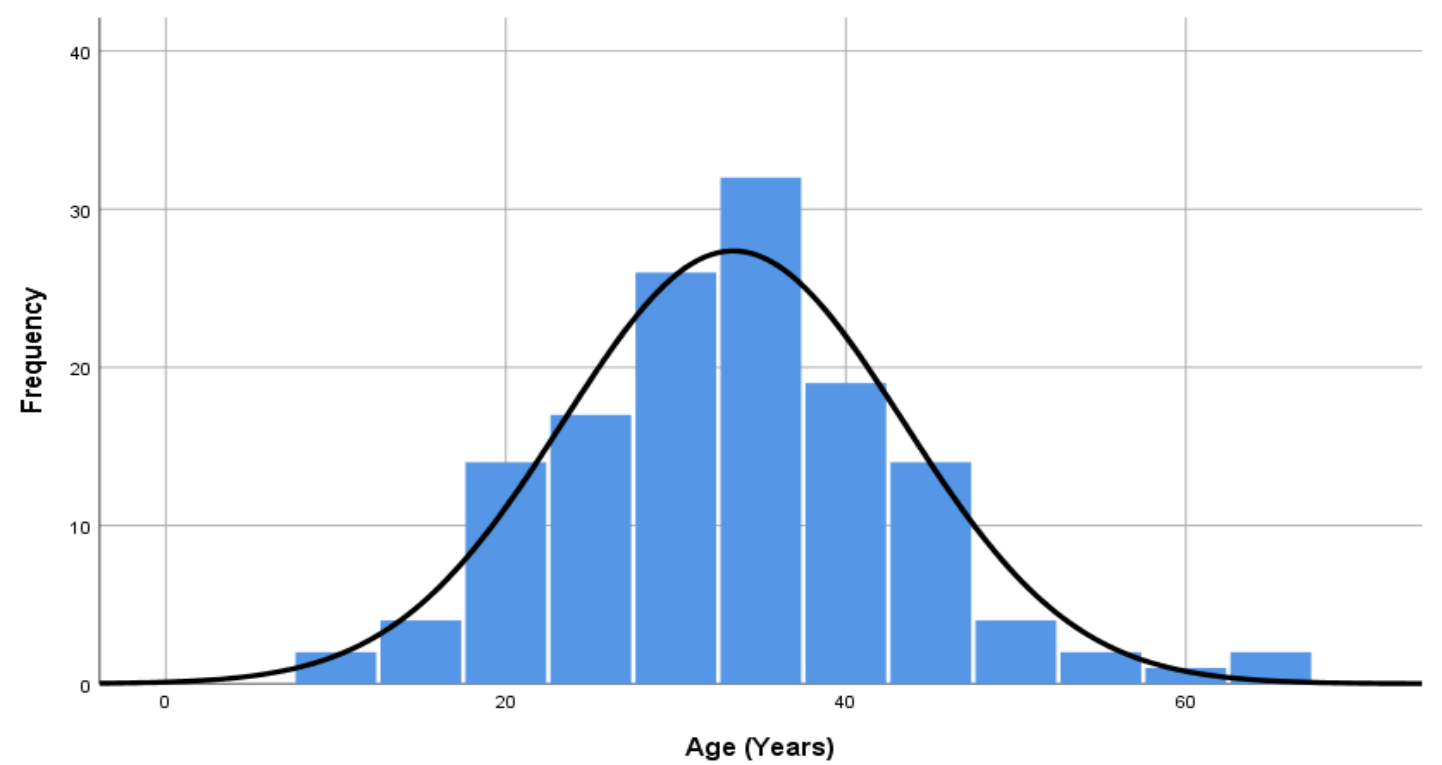

Table 2: Association of UAS Score with Gender

\begin{tabular}{|l|c|c|c|c|c|c|c|c|}
\hline \multirow{2}{*}{ UAS Score } & \multicolumn{4}{|c|}{ Gender } & \multicolumn{2}{c|}{ Total } & \multicolumn{2}{c|}{ Chi-Square Test } \\
\cline { 2 - 8 } & \multicolumn{2}{|c|}{ Male } & \multicolumn{2}{c|}{ Female } & \multicolumn{2}{|c|}{} \\
\cline { 2 - 8 } & $\mathbf{N}$ & $\mathbf{\%}$ & $\mathbf{N}$ & $\mathbf{\%}$ & $\mathbf{N}$ & $\mathbf{\%}$ & $\chi^{2}$ & $\boldsymbol{P}$ Value \\
\hline Mild Activity & 14 & $43.8 \%$ & 56 & $53.3 \%$ & 70 & $51.1 \%$ & 1.350 & 0.509 \\
\hline Moderate Activity & 11 & $34.4 \%$ & 34 & $32.4 \%$ & 45 & $32.8 \%$ & & \\
\hline Severe Activity & 7 & $21.9 \%$ & 15 & $14.3 \%$ & 22 & $16.1 \%$ & & \\
\hline Total & 32 & $100.0 \%$ & 105 & $100.0 \%$ & 137 & $100.0 \%$ & & \\
\hline
\end{tabular}

43.8\% patients in the Gender: Male group had UAS Score Mild Activity. 34.4\% patients in the Gender: Male group had UAS Score Moderate Activity. $21.9 \%$ patients in the Gender: Male group had UAS Score Severe Activity. 53.3\% patients in the Gender: Female group had UAS
Score Mild Activity. $32.4 \%$ patients in the Gender: Female group had UAS Score Moderate Activity. $14.3 \%$ patients in the Gender: Female group had UAS Score Severe Activity. There was no significant difference in the two groups in terms of UAS Score $(\chi 2=1.350, p=0.509)$.

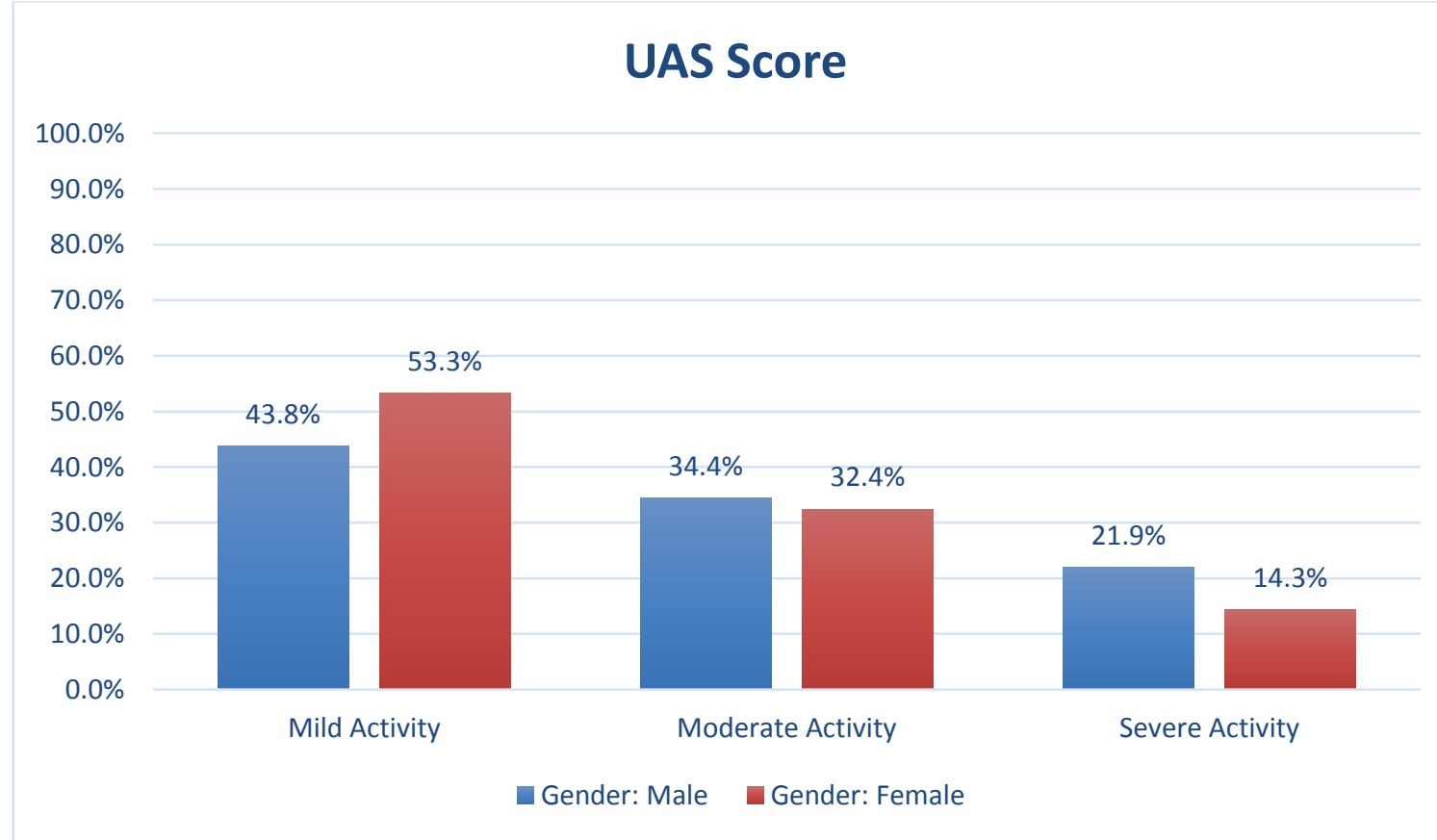




\section{JMSCR Vol||07||Issue||07||Page 595-602||July}

Table 3: Association of UAS Score with Anti-TPO

\begin{tabular}{|l|c|c|c|c|c|c|c|c|}
\hline \multirow{2}{*}{ UAS Score } & \multicolumn{4}{|c|}{ Anti-TPO } & \multicolumn{2}{c|}{ Total } & \multicolumn{2}{c|}{ Chi-Square Test } \\
\cline { 2 - 7 } & \multicolumn{2}{|c|}{ Positive } & \multicolumn{2}{c|}{ Negative } & \multicolumn{2}{c|}{} \\
\cline { 2 - 7 } & $\mathbf{N}$ & $\mathbf{\%}$ & $\mathbf{N}$ & $\mathbf{\%}$ & $\mathbf{N}$ & $\mathbf{\%}$ & $\chi^{2}$ & $\boldsymbol{P}$ Value \\
\hline Mild Activity & 30 & $40.0 \%$ & 40 & $64.5 \%$ & 70 & $51.1 \%$ & 11.003 & 0.004 \\
\hline Moderate Activity & 27 & $36.0 \%$ & 18 & $29.0 \%$ & 45 & $32.8 \%$ & & \\
\hline Severe Activity & 18 & $24.0 \%$ & 4 & $6.5 \%$ & 22 & $16.1 \%$ & & \\
\hline Total & 75 & $100.0 \%$ & 62 & $100.0 \%$ & 137 & $100.0 \%$ & & \\
\hline
\end{tabular}

40.0\% patients in the Anti-TPO: Positive group had UAS Score Mild Activity. 36.0\% patients in the Anti-TPO: Positive group had UAS Score Moderate Activity. $24.0 \%$ patients in the AntiTPO: Positive group had UAS Score Severe Activity. $64.5 \%$ patients in the Anti-TPO: Negative group had UAS Score Mild Activity.
29.0\% patients in the Anti-TPO: Negative group had UAS Score Moderate Activity. 6.5\% patients in the Anti-TPO: Negative group had UAS Score Severe Activity. There was a significant difference in the two groups in terms of UAS Score $(\chi 2=11.003, p=0.004)$.

\section{UAS Score}

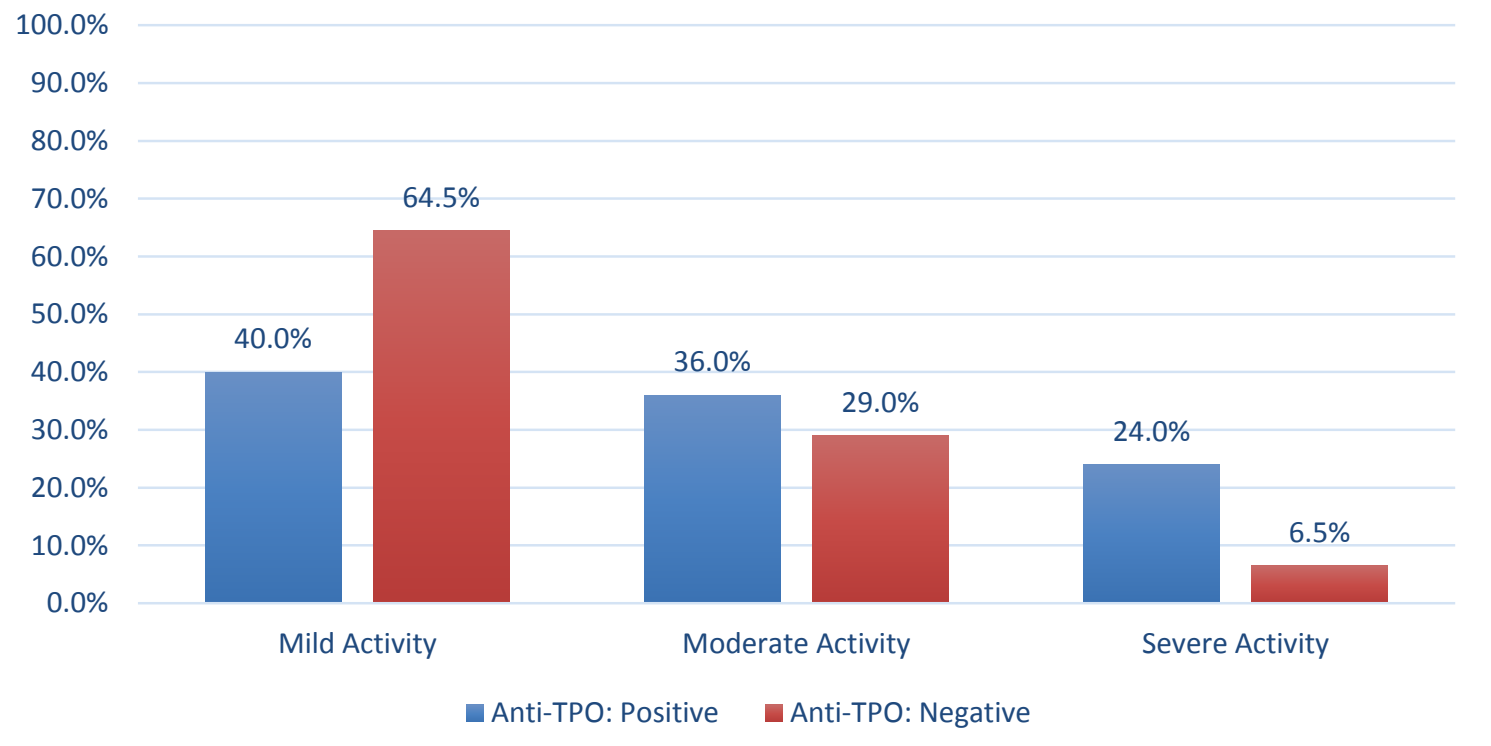

Table 4: Association of UAS Score with ASST

\begin{tabular}{|l|c|c|c|c|c|c|c|c|}
\hline \multirow{2}{*}{ UAS Score } & \multicolumn{4}{|c|}{ ASST } & \multicolumn{2}{c|}{ Total } & \multicolumn{2}{c|}{ Chi-Square Test } \\
\cline { 2 - 8 } & \multicolumn{2}{|c|}{ Positive } & \multicolumn{2}{c|}{ Negative } & \multicolumn{2}{|c|}{$\chi^{2}$} & P Value \\
\cline { 2 - 8 } & $\mathbf{N}$ & $\mathbf{\%}$ & $\mathbf{N}$ & $\mathbf{\%}$ & $\mathbf{N}$ & $\mathbf{\%}$ & $\chi^{2}$ \\
\hline Mild Activity & 65 & $69.1 \%$ & 5 & $11.6 \%$ & 70 & $51.1 \%$ & 42.965 & $<0.001$ \\
\hline Moderate Activity & 23 & $24.5 \%$ & 22 & $51.2 \%$ & 45 & $32.8 \%$ & & \\
\hline Severe Activity & 6 & $6.4 \%$ & 16 & $37.2 \%$ & 22 & $16.1 \%$ & & \\
\hline Total & 94 & $100.0 \%$ & 43 & $100.0 \%$ & 137 & $100.0 \%$ & & \\
\hline
\end{tabular}

69.1\% patients in the ASST: Positive group had UAS Score Mild Activity. $24.5 \%$ patients in the ASST: Positive group had UAS Score Moderate Activity. $6.4 \%$ patients in the ASST: Positive group had UAS Score Severe Activity. 11.6\% patients in the ASST: Negative group had UAS
Score Mild Activity. 51.2\% patients in the ASST: Negative group had UAS Score Moderate Activity. $37.2 \%$ patients in the ASST: Negative group had UAS Score Severe Activity. There was a significant difference in the two groups in terms of UAS Score $(\chi 2=42.965, \mathrm{p}=<0.001)$. 


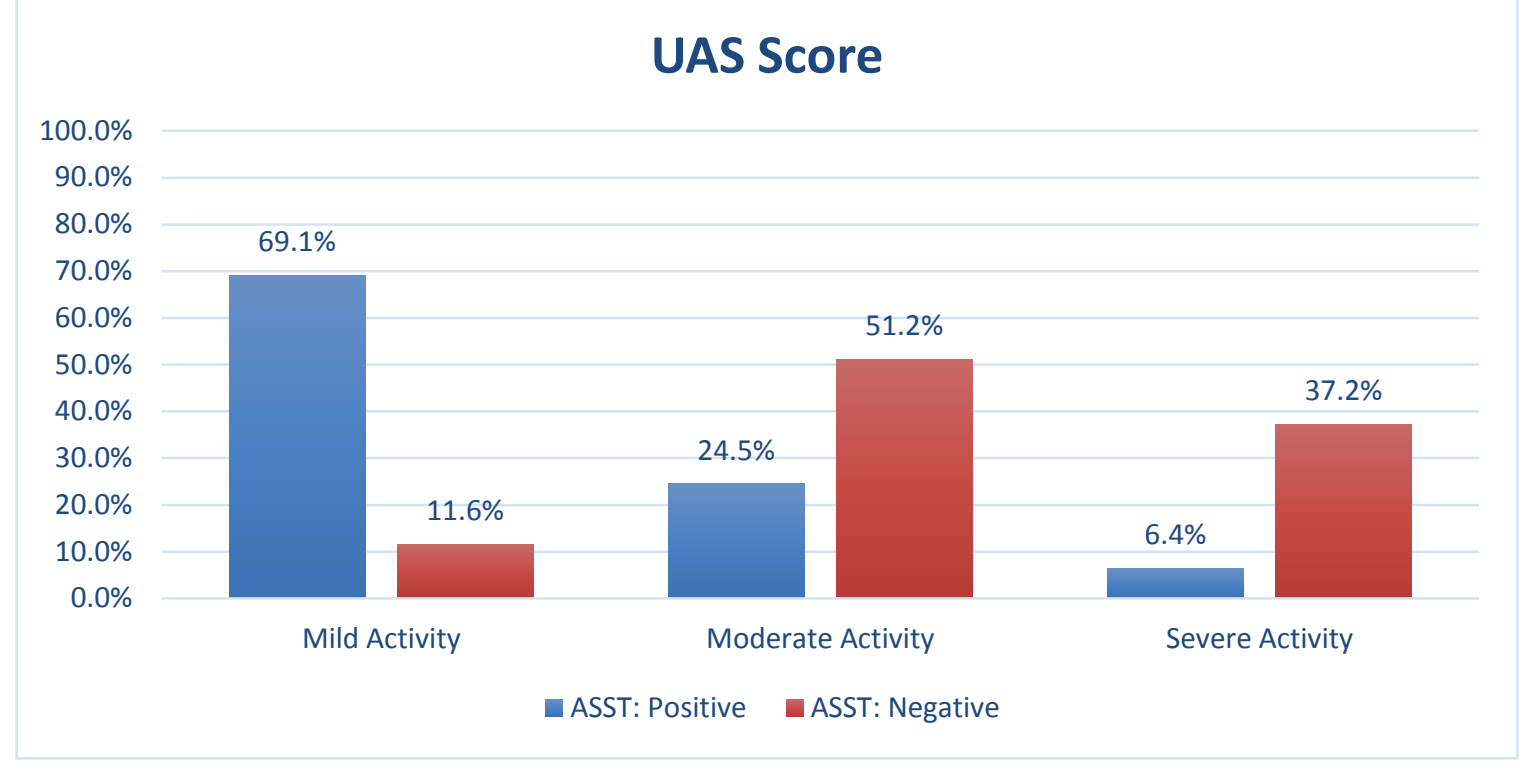

Table 5: Association of Anti-TPO with ASST

\begin{tabular}{|c|c|c|c|c|c|c|c|}
\hline \multirow[t]{3}{*}{ Anti-TPO } & \multicolumn{4}{|c|}{ ASST } & \multirow{2}{*}{\multicolumn{2}{|c|}{ Total }} & \multirow{3}{*}{$\begin{array}{c}\text { McNemar's Test } \\
\text { P Value }\end{array}$} \\
\hline & \multicolumn{2}{|c|}{ Positive } & \multicolumn{2}{|c|}{ Negative } & & & \\
\hline & $\mathbf{N}$ & $\%$ & $\mathbf{N}$ & $\%$ & $\mathbf{N}$ & $\%$ & \\
\hline Positive & 38 & $40.4 \%$ & 37 & $86.0 \%$ & 75 & $54.7 \%$ & 0.061 \\
\hline Negative & 56 & $59.6 \%$ & 6 & $14.0 \%$ & 62 & $45.3 \%$ & \\
\hline Total & 94 & $100.0 \%$ & 43 & $100.0 \%$ & 137 & $100.0 \%$ & \\
\hline
\end{tabular}

40.4\% patients in the ASST: Positive group had Anti-TPO Positive. 59.6\% patients in the ASST: Positive group had Anti-TPO Negative. 86.0\% patients in the ASST: Negative group had AntiTPO Positive. $14.0 \%$ patients in the ASST: Negative group had Anti-TPO Negative. There was no significant disagreement between AntiTPO and ASST (McNemar's Test: $p=0.061$ ).
There was significant agreement between the two tests (kappa $=-0.407, \mathrm{p}<0.001$ ).

The sensitivity and specificity of Anti-TPO as compared to ASST was $59.6 \%$ and $86 \%$ respectively, with negative TPO denoting a positive ASST,

\section{Anti-TPO}

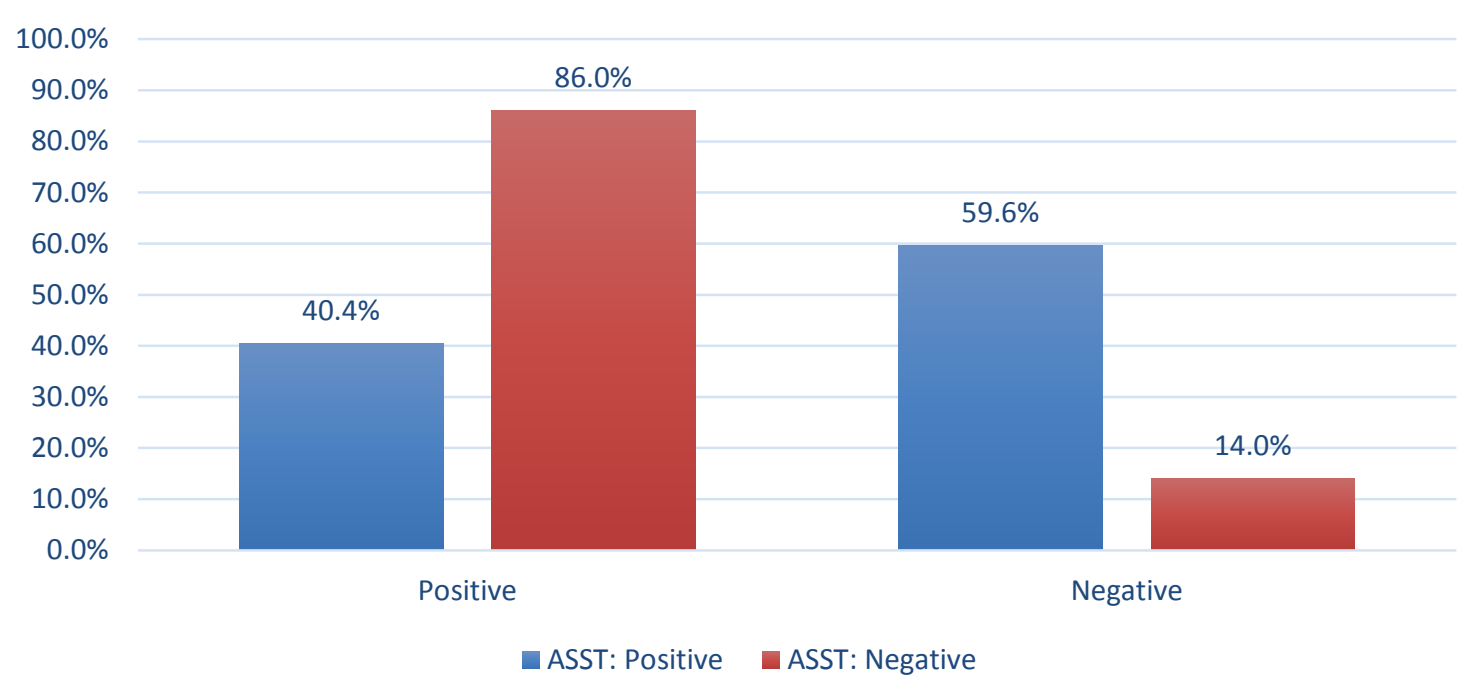




\section{Conclusion}

We can conclude from our study that gender of patients has no significant association with severity of CAU but anti TPO has strong association with UAS score hence with severity of CAU. Even ASST positivity was found to be strongly associated with disease severity. Hence, inference drawn is that all CSU patients despite of their gender should be advised both ASST and Anti TPO.

\section{Acknowledgement}

Foremost, I would like to thank the ethical committee of my college for giving me a chance to do this research.

A very special and sincere gratitude goes to my advisor and my co investigator Dr (Prof) R G Singh for his continuous support and guidance throughout study period.

I wish to express my thanks to Dr (Prof) MS Siddique who has guided me in writing this research.

I want use this opportunity to thank my junior resident Dr. Achlesh for his cooperation during this study.

Last but not least I would like to show my gratitude to my husband Dr Rakesh Chandra Chaurasia and my Parents who have always stood by my side for the motivational support during study.

\section{Sources of support in the form of grants: No.}

\section{Reference}

1. Mlynek A, Maurer M, Zalewska A (2008) Update on chronic urticaria: focusing on mechanisms. Curr Opin Allergy Clin Immunol 8: 433-437.

2. Najib U, Sheikh J. The spectrum of chronic urticaria. Allergy Asthma Proc 2009;30:1-10.

3. Leznoff A, Josse RG, Denburg J, Dolovich J. Association of chronic urticaria and angioedema with thyroid autoimmunity. Arch Dermatol 1983;119:636-40.
4. Leznoff A, Sussman GL. Syndrome of idiopathic chronic urticaria and angioedema with thyroid autoimmunity: A study of 90 patients. J Allergy Clin Immunol 1989;84:66-71.

5. Rumbyrt JS, Katz JL, Schocket AL. Resolution of chronic urticaria in patients with thyroid autoimmunity. J Allergy Clin Immunol 1995;96:.901-6.

6. Grattan CE, Sabroe RA, Greaves MW. Chronic urticaria. J Am Acad Dermatol 2002; 46: 645-57.

7. Dreskin SC, Andrews KY. The thyroid and urticaria. Curr Opin Allergy Clin Immunol 2005;5:408-12.

8. Kaplan AP. Chronic urticaria: Pathogenesis and treatment. J Allergy Clin Immunol 2004;114:465-74.

9. Hide M, Francis DM, Grattan CE, et al. Autoantibodies against the high-affinity IgE receptor as a cause of histamine release in chronic urticaria. $\mathrm{N}$ Engl $\mathrm{J}$ Med. 1993;328:1599-604.

10. Sabroe RA, Seed PT, Francis DM, Barr RM, Black AK, Greaves MW. Chronic idiopathic urticaria: comparison of the clinical features of patients with and without anti-Fc epsilon RI or anti- IgE autoantibodies. J Am Acad Dermatol. 1999;40:443-50.

11. Vikramkumar AG, Kuruvila S, Ganguly S. Autologous serum skin test as an indicator of chronic autoimmune urticaria in a tertiary care hospital in South India. Indian dermatology online journal. 2014 Dec;5(Suppl 2):S87.

12. Najafipour M, Zareizadeh M, Najafipour F. Relationship between Chronic urticaria and autoimmune thyroid disease. Journal of advanced pharmaceutical technology \& research. 2018 Oct;9(4):158.

13. Kulthanan K, Jiamton S, Gorvanich T, Pinkaew S. Autologous Serum Skin Test in Chronic Idiopathic Urticaria: Prevalence, Cor-relation and Clinical 
Implications. Asian Pacific journal of allergy and immunology. 2006 Dec 1;24(4):201.

14. George M, Balachandran C, Prabhu S. Chronic idiopathic urticaria: comparison of clinical features with positive autologous serum skin test. Indian Journal of Dermatology, Venereology, and Leprology. 2008 Mar 1;74(2):105.

15. KikuchiY, FannT, and Kaplan, AP. Antithyroid antibodies in chronic urticaria and angioedema. Journal of Allergy and clinical immunology.2003Jul1;112(1):218.

16. Bakos N, Hillander M. Comparison of chronic autoimmune urticaria with chronic idiopathic urticaria. Int $\mathrm{J}$ Dermatol. 2003;42:613-5.

17. O Donnell BF, Francis DM, Swana GT, Seed PT, Kobza Black A, Greaves MW. Thyroid autoimmunity in chronic urticaria. Br J Dermatol. 2005;153:331-5.

18. Yadav S, Kanwar AJ, Parsad D, Minz RW. Chronic idiopathic urticaria and thyroid autoimmunity: Perplexing association. Indian J Dermatol. 2013;58:325.

19. Jindal R, Roy S, Nagrani P. Chronic idiopathic urticaria and autoimmunity: frequency and association in patients with positive versus negative autologous serum skin test. Int J Res Med Sci 2017;5:11036.

20. Aamir IS, Tauheed S, Majid F, AtifA. Frequency of autoimmune thyroid diseasein chronic urticaria.J Coll Physicians Surg Pak 2010 Mar1;20(3):158-61. 